\title{
Figuras mitológicas y personajes del mundo clásico en la poesía de García Lorca. Fundamentos y procedimientos creativos
}

ABSTRACT: The presence of the mythological figures and characters of the classical world in the poetry of García Lorca informs the principles or fundamental concepts that guide the poet. The most important ones are: 1. Raising a real-life or an imaginary character to a mythological category by means of comparison and identification. 2. Offering a new vision of a mythological character through different procedures such as substitution, addition, impersonation and reinvention. 3. Supporting the poetical content, thus enhancing its emotional charge. 4. Transmitting only the content of some classical references through descriptive, suggestive or imitative language.

Keywords: classical world, mythological figures, characters, principles, procedures.

RESUMEN: La presencia de figuras mitológicas y personajes del mundo clásico en la poesía de García Lorca responde a unas ideas matrices o fundamentos que sirven de guía al poeta. Los más relevantes son: 1. Elevar a categoría mitológica a un personaje de la vida real o imaginaria, para ello acude a la comparación y la identificación. 2. Dar una visión nueva de algún personaje mitológico, utilizando diferentes procedimientos como la sustitución, adición, suplantación y reinvención. 3. Apoyar el contenido poemático, intensificando así su carga emocional. 4. Transmitir únicamente el contenido de algunos referentes clásicos mediante un lenguaje descriptivo, sugeridor o imitativo.

Palabras clave: mundo clásico, figuras mitológicas, personajes, fundamentos, procedimientos. 
La presencia de figuras mitológicas y personajes del mundo antiguo grecolatino en la poesía de Federico García Lorca responde a unas ideas matrices, unas guías que el poeta de forma consciente o inconsciente tenía en su mente. Tras un análisis es posible llegar a determinar estos fundamentos cardinales, si no de todos, al menos de los más relevantes. Cuatro son estos pilares en torno a los cuales se organizan y cobran sentido la gran mayoría de los referentes clásicos indicados.

\section{Un elemento real o ficticio es elevado a la categoría mítica}

Mediante este primer procedimiento se saca de su cotidianidad el elemento real para darle un tratamiento mitológico. Para ello Lorca se vale de la comparación y de la metáfora o identificación, dos procedimientos comunes al alcance de cualquier poeta

El procedimiento de la comparación, el más tradicional, es menos sugestivo y de menor fuerza que la identificación. García Lorca lo emplea de forma muy limitada. El elemento real, en los casos más notables, va desde un personaje concreto conocido por el propio poeta, pasando por un personaje genérico y de carácter representativo, hasta llegar a la propia voz lírica. Se trata en el primer caso de Juan Breva, cantaor flamenco malagueño de gran fama. García Lorca lo compara con Homero (I, 204), ${ }^{1}$ elevándolo así a la más alta categoría como creador y cantor, porque para el poeta «El cantaor [...] saca las viejas esencias dormidas y las lanza al viento envueltas en su voz» (III, 215). Otro remite a un personaje genérico y representa a aquellas mujeres andaluzas sin hijos, muy a su pesar, que en el transcurso del tiempo nadie ha fecundado. García Lorca acude a Ceres, su signo opuesto, ya que se trata de la diosa de la cosecha y la fecundidad, con la finalidad de poner más de relieve su drama:

Como Ceres dieras tus espigas de oro

si el amor dormido tu cuerpo tocara.

Otros momentos remiten al yo lírico. Las figuras mitológicas con las que establece la comparación son el Amor (= Cupido) y Dafne, en plena consonancia ambos con los contenidos poemáticos. Se trata en el primero de ellos de un «yo»

1. Citaremos las obras en verso de García Lorca por: Obras Completas I. Verso. Edición de Arturo del Hoyo, 22 a edición, Madrid, Aguilar, 1992; y las obras en prosa por Obras Completas III. Prosa-Dibujos. Edición de Arturo del Hoyo, Madrid, Aguilar, 1987. 
abandonado y aislado, un «yo» desasistido. Se compara con el Amor, pero en su versión más triste, en su falta absoluta que es la que produce llanto y dolor: «pues soy como el mismo Amor, / cuyas flechas son de llanto, / y el carcaj el corazón» (I, 20). En el segundo caso el yo lírico encuentra su equivalente en una Dafne varonil (I, 126), convertido en chopo para entender el lenguaje del agua en su poema «Manantial». El origen de este tipo de transformaciones se encuentra, según Javier Salazar, en las semejanzas y correspondencias entre la anatomía de los hombres y la morfología de las plantas (1999: 67).

La metáfora o identificación es el procedimiento de más fecundidad y de una mayor fuerza poética sugestiva. El poeta identifica el elemento real y el referente clásico, pasando las cualidades de este último al primero. Las identificaciones ${ }^{2}$ siguen en su elaboración distintas vías o caminos, podríamos decir distintos procesos mentales-imaginativos que de forma consciente o inconsciente dan como resultado una metáfora. Básicamente, García Lorca acude a tres vías o procesos: el acervo cultural, la evocación y la deducción.

El primero tiene su punto de partida en el acervo cultural. La base para la identificación procede en su inicio de la tradición cultural. De aquí surgen metáforas del tipo: «Venus del mantón de Manila que sabe / del vino de Málaga y de la guitarra» (I, 40). En esta identificación entre Venus y la mujer andaluza, han concurrido dos elementos culturales en su constitución: los orígenes romanos de Andalucía y la frecuente y habitual equiparación de aquellas mujeres hermosas y bellas con Venus como si se trataran de diosas. ${ }^{3} \mathrm{O}$ esta otra donde las raíces romanas andaluzas se encuentran en el origen: «Señores guardias civiles: /aquí pasó lo de siempre. Han muerto cuatro romanos / y cinco cartagineses» (I, 399). La valentía y dignidad con la que se enfrentan unos gitanos le lleva al poeta a esta identificación, como si fueran héroes épicos del pasado.

La identificación puede desarrollarse a lo largo de un poema. Es lo que tenemos en «Venus» (I, 323), la sombra de Juan Ramón Jiménez, su correlato

2. Se han descrito diferentes tipos de metáfora, como las puras, las atributivas, aposicionales, sinestésicas, etc. Remitimos para ello al estudio de Miguel García Posada (1982: 87-108) que, aunque trata sobre Poeta en Nueva York, puede perfectamente aplicarse al resto de la poesía de Lorca, y al artículo de Vicente Cristóbal (2006) «Imágenes lorquianas de cuño clásico: metonimias y metáforas mitológicas», que aborda de forma general este tipo de figuras aplicadas a la mitología en la poesía lorquiana. Nosotros seguiremos el título genérico de identificaciones porque lo que nos interesa es poner de relieve las vías o procesos que han llevado a Lorca a esta figura poética.

3. Por citar algún ejemplo cercano de otro poeta de su misma generación, Rafael Alberti. Este identifica con Venus prácticamente a aquellas mujeres que veía en los cuadros que contemplaba en el Museo del Prado, llevaran o no este rótulo. «La Madre de Dios, Nuestra Señora», de Tiziano, es para el poeta una «Afrodita de oro» (Alberti, 1988: 301). También a mujeres de la vida real como la niña de 15 años de su poema «Venus interrumpida» (Alberti, 1988: 455). 
mítico. Una joven muerta tendida en su cama es a ojos del poeta una Venus («Así te vi», dice el propio poeta), estableciendo un paralelismo entre algunos de los elementos propios de esta diosa y elementos reales. Venus es la joven muerta; la concha es la cama donde yace esta joven, la espuma son las sábanas y el alba es el mar por donde surca la joven, como certeramente señala Miguel Ángel Márquez (1994: 139). Otros datos que aparecen en el poema, como «desnuda de flor y brisa», nos llevan al cuadro del Nacimiento de Venus de Botticcelli. ${ }^{4}$

Otras identificaciones que parten de la tradición cultural tienen como figura mitológica a Narciso, con el que se ha asociado la figura del joven apuesto. Lorca no es indiferente a esta asociación, de aquí surge la equiparación de un estrello imaginado como un galán con un «Narciso de plata / en lo alto del agua» ( $\mathrm{I}, 868)$. Se trata en realidad de una estrella masculinizada por el poeta en «Un estrello», título del poema. Lorca se la imagina como un galán, bajo el siguiente proceso identificativo: estrella $=$ estrello $=$ galán $=$ Narciso. En otro momento, es un niño, convertido en muchacho, el que identifica con Narciso. Al borde de un río, resbala y se pierde en el río, se ahoga. Es la sombra de Debussy. Lorca para tal identificación se ha fijado ahora no en la belleza del joven sino en su ahogamiento y fusión con el agua:

Cuando se perdió en el agua comprendí. Pero no explico.

(I, 325-326)

Hay en este poema una idea panteísta de fusión con la naturaleza. Es posible que Lorca la tomara de Juan Ramón Jiménez (1990: 750), quien, para hacer frente a las críticas sobre cierto «misticismo narcisista» que se le atribuía, escribe: «entiendo por narcisismo incorporación del individuo a la naturaleza universal». En Conversaciones con Juan Ramón de Ricardo Gullón, Juan Ramón da una vez más esta visión del mito: «El hombre Narciso es el panteísta que quiere reintegrarse en la naturaleza. Es un suicida en su forma de hombre; pero no de su alma, porque cree que esta se va a fundir con la naturaleza. Si se arroja al agua es precisamente por eso: para buscarla» (Gullón, 1958: 121). De aquí los versos un tanto misteriosos del final del poema de Lorca que siguiendo esta línea cabe interpretar diciendo que el poeta comprende esa fusión con la naturaleza, pero no sabe o no puede explicarla.

La segunda vía es la más fértil. Tiene su punto de partida y desarrollo solo en la imaginación del poeta. Surge en su mente como consecuencia de una

4. Famoso es este cuadro donde surge Venus de una concha entre flores y guiada por dioses alados. Rafael Alberti (1988: 282) en el poema que dedica a Botticcelli, una especie de traducción en palabras del mismo, emplea la misma palabra «brisa» . 
«evocación». Un elemento de la vida real le lleva por vía de la evocación a identificarlo con un elemento de la antigüedad greco-latina, normalmente un personaje mitológico. El propio García Lorca nos da cuenta de este procedimiento en su poema «Palmera»:

\author{
Te dan aire de negra \\ tus adornos de dátiles \\ y evocas la Gorgona \\ pensativa. (I, 784)
}

La palmera le sugiere por vía emocional una Gorgona pensativa. Evidentemente nada tienen que ver una palmera y una Gorgona. Pero una vez dada la identificación es posible ver algún elemento común como la base que ha llevado al poeta a tal identificación. Las Gorgonas son estos seres fantásticos y monstruosos que al que miraban lo dejaban petrificado. La Gorgona más famosa es la Medusa, a la que sin duda se está refiriendo. Esta aparece en la mitología con cabello de serpientes. Bien podría ser esta la base, al ver las ramas de la palmera como si fueran serpientes que surgen de su cabeza.

Elementos inertes cobran vida por esta vía, sobre todo del mundo vegetal. Javier Salazar (199: 33) ha puesto en evidencia que el poeta tenía cierta predilección por la formación de imágenes a partir de este mundo. Y una buena parte de las identificaciones pertenecen precisamente a este ámbito. A sus ojos, las plantas, los árboles y sus frutos estaban dotados de vida, podían pensar y sentir al modo humano, es más, con mayor intensidad, al modo mítico. Por esta razón, una chumbera es un Laocoonte (I, 220), que siente un dolor tan intenso como el propio personaje mitológico o un chopo solitario es «el Pitágoras de la casta llanura» (I, 104) o la granada es «hermana de carne de Venus» $(\mathrm{I}, 107)$ con tono claramente sensual.

Pero el poeta no se limita a este tipo de identificaciones del mundo vegetal: cualquier elemento inerte o animado puede ser blanco de su imaginación siguiendo la tradición de los románticos y simbolistas a la que hay que unir la tradición folklórica, como ha patentizado Javier Salazar. De aquí que una guitarra sea un «Polifemo de oro» (I, 217) y la luna un «unicornio gris y verde» (I, 345). O bien, Estrella la gitana, una «danaide del placer» y un «femenino Silvano» (I, 50); y el personaje bíblico Salomé, una «medusa del desierto» (I, 616). Incluso no se escapa a su imaginación el arte de Dalí, al que identifica con «ancha luz de Minerva» (I, 955), un equivalente a Apolo, por su justa y ordenada medida, en oposición a la inspiración dionisíaca, desordenada, propia del dios Baco.

Las identificaciones apuntadas responden todas ellas a la equivalencia entre elemento real en primer plano y referente clásico en segundo, pero la imagina- 
ción de Lorca da la vuelta a este esquema, invierte los términos y sitúa el referente clásico en primer plano y el elemento real en segundo. Este procedimiento es más bien escaso. En el poema «Él» de La selva de los relojes, dice que «la verdadera esfinge / es el reloj» (I, 832), indicando con ello que el misterio ya no se encuentra encerrado en esta figura mitológica sino en algo más moderno, como es un reloj, que encierra el misterio del tiempo y en definitiva el futuro. Narciso, por su parte, se identifica con el sufrimiento amoroso del propio poeta: «Narciso. / Mi dolor. / Y mi dolor mismo» (I, 374).

La figura mitológica al aparecer en primer término produce cierto contratiempo en la mente del lector ya que le obliga de manera consciente o inconsciente a una representación muy definida, en primer lugar, dada por el mundo mitológico que puede coincidir o no en algún rasgo con el elemento real. En el último caso citado, la figura de Narciso, cuya representación más común es imaginársela mirándose en el agua, al identificarla a continuación con el dolor del propio poeta, no deja de producir cierto conflicto, que lleva al lector o bien a buscarle alguna semejanza que en un primer momento no ve o simplemente a seguir leyendo otro poema, sin buscarle explicación alguna por la disparidad tan grande, incrementada por la representación en primer término de la figura mitológica. Esta sería la diferencia con el tipo de identificaciones donde el elemento real se encuentra en primer lugar. En un ejemplo ya citado, cuando García Lorca equipara una chumbera con un Laocoonte, la disparidad entre ambos elementos resulta también patente, pero la «chumbera» al situarla en primer término nos transmite una idea de retorcimiento que inmediatamente al leer la figura de Laocoonte, tratamos de transferir para buscar el elemento base de tal equiparación. La identificación resulta más fácil de resolver, ya que la figura mitológica no actúa como intensificadora de tal disparidad, al no presentarse en primer término. Abre así toda una serie de posibilidades que de estar en primer lugar se nos niega en principio.

La tercera vía por la que el poeta llega a la identificación es la deductiva, donde se produce no una evocación más o menos irracional, sino que llega a la misma por la vía de la reflexión y el razonamiento. En el poema «Sésamo» identifica a la naturaleza con Narciso. Podemos seguir su razonamiento fácilmente. Parte de la idea de que la verdadera realidad es su propio reflejo que tiene su manifestación en la naturaleza. «El reflejo / es lo real», así comienza el poema, y sigue unos versos más, invirtiendo el mismo aserto, «Lo real es el reflejo», en una figura quiasmática, no carente de significado, ya que el poeta nos viene a decir mediante esta figura que la realidad y su reflejo son lo mismo. Si la naturaleza es en definitiva un reflejo, el personaje mitológico relacionado con esta idea no puede ser otro más que Narciso. Y de aquí termina concluyendo que la 
naturaleza es «el Narciso eterno» (I, 691). Podemos esquematizarlo del siguiente modo: realidad $=$ reflejo $=$ naturaleza $=$ Narciso eterno.$^{5}$

La importancia del reflejo en García Lorca como la forma en la que se manifiesta la existencia no ya de la naturaleza en su totalidad, sino de algo más concreto resulta recurrente. Ya en el prólogo a su libro de poemas de 1921, dice: «En estas páginas va el reflejo fiel de mi corazón y de mi espíritu, teñido del matiz que le prestara, al poseerlo, la vida palpitante en torno recién nacida para mi mirada» $(\mathrm{I}, 5)$. Sus poemas reflejan, es decir, representan y al mismo tiempo son su corazón y su espíritu. ${ }^{6}$

En su poema «Pregunta» identifica tres personajes pertenecientes a tres ámbitos distintos: «Adán, Paris y Newton» (I, 797). Uno de ellos es de la antigüedad clásica. La base de tal identificación surge en la imaginación de Lorca ante la idea de que los tres comparten una misma inquietud: la curiosidad, el deseo de saber, la belleza y lo prohibido, todo ello representado en la manzana. A esta base llega el poeta por vía de la reflexión y la deducción.

Para poder entender este proceso deductivo resulta imprescindible recurrir a otros dos poemas suyos que preceden al mencionado. Me refiero a «El último paseo del filósofo» y sobre todo a «Réplica». En el primero aparece solo la figura de Newton, que después de dar un paseo, «volvía a su casa / soñando inmensas pirámides / de manzanas» (I, 795), a saber, soñando con indagar más y más. En el segundo se produce la identificación entre Adán y Newton, y nos desvela la identificación entre manzana y ciencia. He aquí los versos:

\author{
Adán comió la manzana \\ de la virgen Eva. \\ Newton fue un segundo Adán \\ de la Ciencia. (I, 796)
}

Al igual que Adán comió del fruto prohibido de la manzana, producto del árbol de la ciencia del bien y del mal, que representa la curiosidad y ganas de saber (impulsos que le llevaron al propio Adán a comer este fruto), a Newton la misma curiosidad y deseos de descubrir algo nuevo le llevan a comer (o entregarse a) de la Ciencia, equiparándose así con Adán. Y en los resultados de tal acción vemos la idea de belleza que acompaña al saber y la curiosidad:

5. Ya hemos tenido ocasión de señalar la idea panteísta que sobre el mito de Narciso hay en Lorca. Su hermano Francisco pone de relieve que era una de las ideas que tenía muy presentes (Fr. GarcíaLorca, 1980: 87).

6. La idea de que la realidad es un reflejo no es nueva. William Blake, según Javier Salazar (1999: 20-21), «afirmaba que la naturaleza es un reflejo del mundo celestial». 


\author{
El primero conoció \\ la belleza. \\ El segundo un Pegaso \\ cargado de cadenas. (I, 796)
}

La Ciencia es para el poeta «un Pegaso cargado de cadenas»: algo costoso, como puede resultar a Pegaso el poder emprender el vuelo si está cargado de cadenas, pero bello, si seguimos con el paralelismo.

García Lorca nos ha dado las claves de la identificación de Adán $=$ Newton; manzana $=$ ciencia $=$ belleza. $\mathrm{Y}$ ya en el poema «Pregunta» incorpora un tercer personaje, Paris. Este también impulsado por la belleza y lo prohibido decide raptar a Helena. Los tres son transgresores de lo establecido, normal y corriente. Sienten un impulso irresistible por conocer, desentrañar misterios, en definitiva, por comer del fruto prohibido, a pesar de lo costoso que pueda ser y el riesgo que ello lleva consigo. Solo a través de un proceso reflexivo-deductivo, como hemos podido observar, le ha sido posible a García Lorca llegar a la identificación de estos tres personajes: Adán, Paris y Newton.

\title{
2. Visión del mito distinta de la que la tradición legó
}

Un segundo pilar sobre el que se asienta y explica la presencia de referentes clásicos, es la de presentar mitos de forma diferente a como la tradición los ha transmitido. La idea de transformar el mito clásico con la finalidad de darle una nueva interpretación es algo que el propio poeta manifiesta en una carta dirigida a Melchor Fernández Almagro: «estoy haciendo interpretaciones modernas de figuras de la mitología griega, cosa nueva en mí y que me distrae muchísimo» (III, 726). Los procedimientos para llegar a esta nueva visión los denominaremos: sustitución, adición, suplantación y reinvención.

El procedimiento de sustituir un elemento clásico por otro creativo y de añadir algo nuevo queda evidenciado en su poema «El sátiro blanco»:

Sobre narcisos inmortales

dormía el sátiro blanco.

Enormes cuernos de cristal

virginizaban su ancha frente.

El sol, como un dragón vencido,

lamía sus largas manos de doncella. (I, 1095) 
El poeta da una visión del sátiro muy distinta de la tradición clásica. Le asigna características creativas propias de su imaginación: un color blanco, unos cuernos de cristal (adición respecto a sus calificativos) y unas manos [en vez de pezuñas] de doncella (sustitución). Con ello el poeta cambia la imagen que sobre este ser fantástico nos muestra la tradición, creando una nueva repleta de inocencia y pureza.

Siguiendo este procedimiento, García Lorca opera dos tipos de transformaciones, las denominaremos parcial y total. Consideramos que es parcial cuando el personaje mitológico sigue conservando algunas de las características o funciones que determina la tradición clásica. El personaje es perfectamente reconocible en alguna de sus funciones o características. Una muestra del primer tipo la podemos ver en los siguientes versos de su poema «[El mar]»:

Y en las cuevas de oro

las sirenas ensayan

una canción que duerma

al agua. (I, 605)

Los elementos reconocibles asociados a las sirenas son las cuevas donde vivían y, sobre todo, una de sus funciones en el lexema canción. Lo creativo está en que las cuevas sean de oro (adición) y que la finalidad de la canción que están ensayando sea la de dormir al mar, cuando en realidad las sirenas lo que hacían con sus cantos, como es conocido de todos, era que los barcos se estrellaran y naufragaran (sustitución). ${ }^{7}$

La transformación parcial puede afectar a toda una historia mitológica, como muestra su poema de tono burlesco «Salmo recordatorio», donde intervienen: Polifemo, Galatea, Acis y Góngora (adición). Lorca mantiene intacto el mito según la tradición cultural pero al final aparece la figura de Góngora, al que reclama Galatea arrojando de su lado a Acis. El poeta lo que viene a decir es sim-

7. Otros ejemplos podríamos citar como el que nos ofrece su poema «Se ha puesto el sol», en los siguientes versos: «La Penélope inmensa de la luz / teje una noche clara» (I, 75). Reconocemos el lexema teje, actividad que llevaba a cabo Penélope a la espera de la llegada de Ulises, pero obviamente no teje una noche clara (adición), ni se nos presenta inmensa de luz (adición). Estos dos elementos que añade el poeta sirven para indicarnos que realmente de quien está hablando no es de Penélope sino de la luna. Igualmente, cuando dice en su poema «Canciones del día que se va»: «En la tarde, un Perseo / te lima las cadenas, / y huyes sobre los montes / hiriéndote los pies» (I, 390). Reconocemos la función de Perseo en la expresión «limar las cadenas», ya que según la mitología liberó a Andrómeda de las cadenas que la tenían sujeta a una roca (Grimal, 1966: 426). Versos que indican el atardecer y la marcha del día. 
plemente que la poesía, representada en Galatea, se siente atraída por Góngora, impulsor de un tipo de poemas dotados de una especial belleza.

Por transformación total entendemos el cambio del personaje mitológico en otro diferente irreconocible a partir de los datos de la tradición. Si en la transformación parcial seguimos reconociendo al personaje mitológico en alguna de sus funciones, como las sirenas en su función de cantadoras, o bien toda una historia, en la transformación total no sucede lo mismo, el personaje mitológico se ha metamorfoseado por obra de la imaginación del poeta en algo completamente diferente. Una muestra significativa en este sentido es su poema «Secretos». Pan convertido en una mariposa:

\author{
¡Ved que locura! \\ Los cuernos de Pan \\ se han vuelto alas, \\ y como una mariposa \\ enorme, \\ vuela por su selva \\ de fuego. \\ ¡Ved qué locura! (I, 1012)
}

Se produce suplantación cuando un personaje reemplaza a otro desempeñando sus mismas funciones. La diferencia con la transformación total consiste en que esta última se trata de una simple metamorfosis, y en el caso de la suplantación se trata además de asumir las funciones de otro. Aparece de forma tímida, ${ }^{8}$ pero se encuentra algún caso como vemos en su poema «Caístro». En realidad se trata de un dios de la Antigüedad que representa un río que lleva su nombre (Grimal, 1966: 80). García Lorca se lo imagina con alas sobre cuyo plumaje se «resbala la noche fría» (I, 234), suplantando en sus funciones a Caronte, remolcando «río adelante / la barca de los muertos» (I, 234). El único nexo reconocible es la palabra «río», que en el poema es una clara alusión a la laguna Estigia. ${ }^{9}$

Por reinvención entendemos la composición de un poema que en alguna medida tiene que ver con algún dato o historia mitológica. Solo un análisis minucioso y perspicaz del mismo nos lleva a la fuente clásica o al menos a un recuerdo de la misma. Tal son los casos del poema «Oda y burla de Sesostris y

8. Rafael Alberti (1988: 291) emplea este procedimiento de forma decidida. Las Furias, por ejemplo, suplantan a las Musas como diosas de la inspiración, en el poema que dedica a Miguel Ángel.

9. Expresión parecida a «la barca de los muertos» la encontramos en su poema «Fin»: «Y en el barco de la Muerte / vamos los hombres» (I, 704). 
Sardanápalo», sobre el que García-Posada mostró la vinculación entre lo apolíneo, representado por los griegos, frente a lo báquico, representado por Sesostris y Sardanápalo (García Lorca, 1985: 37) ${ }^{10}$ y del poema «Preciosa y el aire», que recuerda el mito de Bóreas y Oritía contado por Ovidio en sus Metamorfosis (VI, 675-721), algo que ya puso de manifiesto Amado Alonso. Son los casos de mayor creatividad bajo cuyo ropaje semántico se oculta algún elemento o antecedente de la Antigüedad clásica.

\section{Apoyo de las figuras mitológicas a un determinado contenido o clima poético}

García Lorca se sirve de personajes mitológicos con la finalidad de que vayan en apoyo del contenido poemático o clima poético, utilizando cuatro variantes en su manifestación.

\subsection{Crear un determinado ambiente que nos traslada a la antigüedad}

La muestra más evidente es su poema el «Martirio de Santa Olalla», basado en el martirio que sufrió Santa Eulalia en Mérida cuando era una niña en época de Diocleciano. García Lorca se traslada al s. III d. C. para darnos una estampa de aquella época. A ello contribuye la presencia de soldados de Roma, Cónsules y Centuriones. Representan el poder político y militar. Son los encargados de cumplir la orden del Emperador, de castigar a aquellos que no dejen de rendir culto a Jesucristo y no adoren a los dioses paganos. El ensañamiento con la santa, su decapitación, mutilación y posterior quema, la describe el poeta con toda su crudeza, dejando con ello bien claro su muy merecida gloria de Santa.

3.2. Envolver de cierto aire mítico el contenido poemático, intensificando la carga emocional del poema

$\mathrm{Su}$ presencia se genera a partir de la tradición cultural mediante asociaciones directas entre foco temático y personaje mitológico que le viene dado al poeta del exterior, imprimiendo su sello personal. En su poema «Estío» el

10. Para Isabel Román (2003: 396) se trata de «una reminiscencia jocosa del aprendizaje memorístico infantil de la cultura clásica, con las que el adulto ajusta cuentas burlonamente, lo que le lleva a una relectura atrevida del conocimiento mitológico». 
poeta nos presenta un cuadro veraniego centrado en el momento de la siega, su foco temático. Hace acto de presencia Ceres, la figura mitológica estrechamente relacionada con la agricultura, bajo una bella metáfora donde las espigas son sus lágrimas («Ceres ha llorado / sus lágrimas de oro»; I, 823), y ella misma las espigas cortadas («Ceres está muerta / sobre la campiña»; I, 823). Envuelve al poema de cierto halo mítico que nos traslada al mundo antiguo, a la mentalidad de aquellos campesinos plenamente convencidos de que Ceres era la que propiciaba las cosechas.

La presencia de Apolo no podía faltar en un poema cuyo núcleo temático es el laurel. El poema no es otro que «Invocación al laurel». La asociación resulta evidente. El árbol del laurel es a ojos del poeta símbolo de la sabiduría: «formado del cuerpo rosado de Dafne / con savia potente de Apolo en tus venas» ${ }^{11}$ (I, 136). Pero es la figura de Venus la que ocupa un lugar preeminente. Su presencia realza la carga semántica y emocional en los poemas «Mañana», «Mar», «Mediterráneo» $\mathrm{y}$ «Visión». Los cuatro giran en torno al agua, en especial al agua del mar, medio en el que Venus nació, hecho que nos recuerda el poeta en los dos primeros poemas. Se trata, según Rosa Ma Aguilar (1998: 79), de Afrodita Urania, la nacida de la emasculación de Urano, la única, a su juicio, que quizá tiene siempre en mente el poeta. La presencia de esta figura mitológica nos traslada al mundo mítico antiguo y en los cuatro casos la idea generadora es el mar como origen de la vida, fundamentada en el amor, a la que el poeta asocia con Venus en un sistema de equivalencias: mar $=$ vida $=$ amor $=$ Venus. De aquí estos versos repletos de fuerza y vitalidad con los que cierra el último de los poemas citados:

Frente al mar delirante,

vemos

la vida y el amor

al descubierto» (I, 1072)

\subsection{Potenciar una determinada atmósfera cargada de negatividad}

Dos temas estrellas presiden en estos casos el contenido poemático: la muerte y la frustración en el amor. A diferencia del apartado anterior, la asociación con el contenido es meramente subjetiva, solo tiene sentido en el interior del poeta y no es posible buscarle una razón exterior. Significativa resulta la incorporación de personajes mitológicos en algunos poemas de Poeta en Nueva York.

11. Según Javier Salazar (1999: 183), el laurel, a propósito de este ejemplo, podría ser un símbolo de la homosexualidad. A nuestro juicio, representa simplemente el saber. 
La presencia de la muerte, ya obsesiva en su poesía, se hace aquí más patente. $\mathrm{Y}$ a potenciar esta presencia contribuye la incorporación de figuras mitológicas, meras alusiones siguiendo un proceso de elipsis y estilización, como muy bien ya han señalado Rosa Ma Aguilar (1998: 87) e Isabel Román (2003: 395). Así lo podemos evidenciar en su poema «Fábula y rueda de los tres amigos». La continua presencia de la muerte a lo largo de todo el poema adquiere gran intensidad en estos versos:

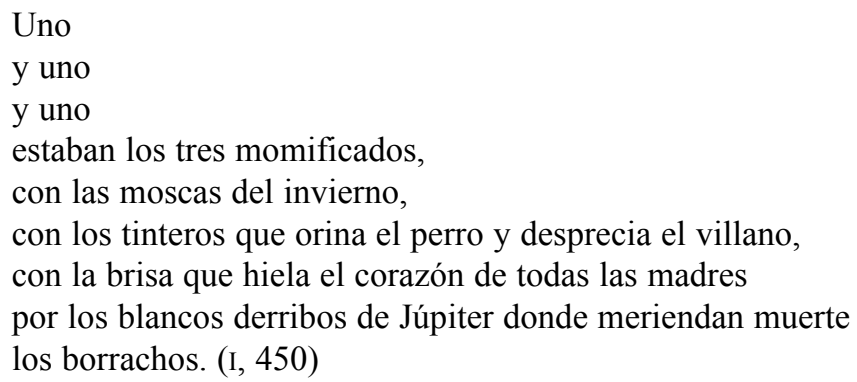

Nos encontramos con la expresión «por los blancos derribos de Júpiter donde meriendan muerte los borrachos». Varias son las interpretaciones que se han dado a la figura de Júpiter. Conocidas son la de Miguel García-Posada y José María Camacho Rojo. Ambos consideran que representa las «creencias y convenciones de la sociedad», represoras del amor homosexual (García-Posada, 1982: 193; Camacho Rojo, 2006: 102). Interesante resulta la interpretación de Andrés Ortega (2012: 327) para quien «los blancos derribos de Júpiter» está indicando de forma metafórica «el derrumbe o caída del cielo, es decir, el final de la noche que da paso al día». Se trata en definitiva de «el amanecer».

Como la poesía se presta a diferentes lecturas, y como prueba están estas distintas interpretaciones, nosotros partimos para nuestra propia lectura del contexto de la estrofa en que se encuentra. La imagen resulta muy plástica, tres amigos se encuentran muertos, momificados, es decir, cosificados, llenos de moscas, a merced del orín de los perros, imagen sobrecogedora para cualquier madre. Solo falta situarles en un espacio, y eso es lo que, a nuestro juicio, indican este par de versos. El propio Jorge Guillén da la clave en el prólogo que escribe a las obras completas de García Lorca editadas por Arturo del Hoyo. Comenta que su amigo configuró estos versos a partir de la expresión «ahí meriendan los borrachos» que había dicho Claudio Guillén, de tres años, «ante unos desmontes con restos rotos de suburbio en las afueras de la ciudad (Valladolid)» (I, LXXXII). Los tres amigos serían unos «despojos», en palabras de Isabel Román (2003: 403), tirados a las afueras de la ciudad en unos desmontes («derribos de Júpiter»), del color blan- 
co de los cadáveres, atribuido por hipálage a derribos. ${ }^{12} \mathrm{Si}$ tenemos en cuenta, siguiendo a María Clementa, que Lorca lo que hace en el poema es «objetivar su amor perdido en una macabra danza» de los tres personajes, protagonistas del poema (García Lorca, 2010: 243), podemos deducir el estado de ánimo del poeta, cómo se sentía ante un amor perdido: como un verdadero despojo tirado y abandonado en un descampado sin ningún ánimo, prácticamente sin vida, como los tres amigos del poema, muertos, helados y momificados.

Representando a la muerte y potenciando la misma se encuentran las «tres ninfas del cáncer» (I, 507) bailando, en clara referencia a las Parcas de su poema «Paisaje con dos tumbas y un perro asirio». Y fuera de Poeta en Nueva York volvemos también a encontrar esta atmósfera negativa con la presencia de la muerte como eje vertebrador. De nuevo, una figura mitológica vendrá a simbolizarla. Será Diana, como representante de la luna, la encargada de simbolizar a la muerte, en el contexto de estos versos:

¡Oh Diana, Diana, Diana vacía!

Convexa resonancia donde la abeja se vuelve loca. (I, 1053)

Su carácter repetitivo intensifica aún más su contenido negativo. Según Andrés Ortega Garrido (2012: 325) «la exclamación invoca primordialmente la pérdida del bosque a favor de la organización urbana, connotación de Poeta en Nueva York». Considera la expresión «Diana vacía» «equiparable a la de un bosque imposible», donde la abeja pierde la razón (Ortega Garrido, 2012: 368). Por nuestra parte, seguimos la opinión de Miguel García Posada (1982: 257) en la que después se basa José María Camacho Rojo (2006: 100), en el sentido de la identificación de Diana con la luna, como símbolo de la muerte, «donde la vida [la «abeja»] perece de manera inevitable».

En todos estos casos el poeta se ha servido de estas figuras mitológicas con ánimo no mitológico, sino simbólico. La mitología va a ser solo el material de que se vale para dar mayor fuerza e intensidad a la presencia de la muerte, contribuyendo a potenciar la atmósfera de negatividad.

La frustración en el amor viene simbolizada en la figura de Apolo. Lorca debió tener muy presente el mito de Apolo y Dafne, que ya hemos mencionado,

12. Junto con estos versos, críticos y estudiosos citan estos otros prácticamente iguales de su poema «Vaca»: «Que ya se fue balando / por los derribos de los cielos yertos / donde meriendan muerte los borrachos» (I, 497). Indican el paso de la vaca al «mundo de los muertos» (Clementa Millán en García Lorca, 2010: 260). Nosotros los mencionamos aquí para ratificar nuestra interpretación en el sentido que igualmente señala el espacio o lugar donde van a parar los muertos desposeídos y despreciados: un lugar abandonado («derribos») donde los cadáveres permanecen «yertos», rígidos. 
pero que se traduce en meras alusiones en Poeta Nueva York, por ese proceso de estilización apuntado. Apolo no consigue alcanzar a Dafne al quedar convertida en el árbol del laurel por obra de Zeus (Grimal, 1966: 125), lo que a ojos del poeta frustra su deseo de unirse con la ninfa. Esta idea, como ya se ha demostrado suficientemente, la aplica a su propia realidad en «Tu infancia en Mentón», a la pérdida de un amor que le ha traicionado y a su búsqueda, en palabras de María Clementa Millán: «trasladarlo al tiempo donde únicamente son posibles las fábulas» (García Lorca, 2010: 243), a saber, al mundo de la imaginación.

En su conocida y estudiada «Oda a Walt Whitman», Lorca se identifica con el poeta estadounidense en su condición de homosexual y en su defensa de tal condición. Como muy bien apuntan estas palabras de María Clementa Millán: «El protagonista (Walt Whitman) manifiesta la legitimidad del ser humano para escoger su sentimiento amoroso» (García Lorca, 2010: 273); o en estas otras de Luis García Montero (1996: 39) el protagonista es ese personaje «que vive con sinceridad las órdenes del deseo», frente a las normas de la sociedad, lo regulado que «se convierte inevitablemente en formas autoritarias de someter las libertades individuales» (García montero, 1996: 44). El poeta opone el amor puro entre hombres frente a la pasión dionisíaca, frente al amor desenfrenado, propio de «maricas». Lo hace mediante la expresión «Apolo virginal» $(\mathrm{I}, 529)$ con la que Lorca se siente solidario. Indica también la falta de descendencia por mantenerse fiel a su homosexualidad, cuya legitimidad ratificará unos versos más adelante: «El cielo tiene playas donde evitar la vida / y hay cuerpos que no deben repetirse en la aurora» (I, 530).

Siguiendo la línea de la no fecundación, de la esterilidad propia de los homosexuales, aparece la figura de Saturno en el poema ya citado, «Tu infancia en Mentón», bajo estos versos: «No me tapen la boca los que buscan / espigas de Saturno por la nieve / o castran animales por un cielo, / clínica y selva de la anatomía» (I, 452). Según Miguel García Posada, al que le sigue José María Camacho, Saturno viene a simbolizar «la represión del amor homosexual» (García Posada, 1982: 193; Camacho Rojo, 2006: 101). Andrés Ortega (2012: 329), la relaciona con «rituales de fecundación o castración». Pero nosotros pensamos que los dos primeros versos mencionados indican la discrepancia del propio poeta frente a aquellos homosexuales que critican la búsqueda, aunque sea sin éxito, de la persona amada, a pesar incluso de haberle traicionado. «No me tapen la boca», indica que no le hagan callar por defender un amor puro «los que buscan espigas de Saturno por la nieve», ${ }^{13}$ a saber, los homosexuales que buscan la unión con

13. Miguel García-Posada (1982: 140), identifica «nieve» con mujer. Para ello se basa en estos otros versos de «Pequeño poema infinito»: «Equivocar el camino / es llegar a la nieve... 
los de su mismo sexo y por lo tanto carente de frutos, ya que el semen de Urano («las espigas») no fructifica en la nieve. Igualmente en los dos versos siguientes citados muestra su oposición a los heterosexuales que critican y reprimen («castran») las relaciones homosexuales.

\subsection{Otra variante más es la de poner de relieve las características de un determinado personaje}

La presencia de Pan y Leda en el poema «Caístro» contribuye a determinar con más precisión las características de este último, mediante un juego poético de negación/afirmación. Se trata del mismo mecanismo que con frecuencia se utiliza para caracterizar a alguien, simultaneando lo que no es y es a la vez. Mediante este mecanismo se precisa más su forma de ser. La negación reafirma la afirmación. «Ni Pan / ni Leda», así da comienzo el poema. El poeta viene a decir que Caístro no es ni un sátiro, ni una ninfa: «Sobre tus alas / se duerme la luna llena», se trata de un ser fantástico de grandes alas. Continua el poema con el mismo juego, hasta que al final nos desvela quién es Caístro, un ser imaginario con forma de ave cuya misión es remolcar «río adelante / la barca de los muertos» (I, 234), suplantando en sus funciones, como ya hemos tenido ocasión de señalar, a Caronte.

Igualmente, por vía negativa trata de caracterizar a una mujer sentida como «lejana», de su soneto «La mujer lejana. Soneto sensual»:

Por ti la Noche y Erebo se vuelven a la Nada,

Febe se apaga lánguida ante ti, humillada

y se escarcha de flores la cabeza de Eros. (I, 927)

Isabel Román comenta que se trata de un elogio convencional a la mujer, a la manera rubeniana «por medio de comparaciones mitológicas», en contraste con Piero Menarini (1986) que lo ve como un reconocimiento a la esterilidad del amor homosexual (Román, 2003: 389). A nuestro juicio el soneto es claro en la línea de Isabel Román. Los versos apuntados tienen como núcleo significativo la belleza y atractivo de la mujer, por eso se la siente como lejana. Ante su belleza tan resplandeciente, la noche y las sombras (Erebo) desaparecen, y el propio

Equivocar el camino / es llegar a la mujer» (I, 547). Considera estos versos una demostración contundente de tal equivalencia, pero en poesía el significado de una expresión igual o parecida puede tener un resultado diferente en contextos distintos, máxime si se trata solo de una palabra como es este caso. 
brillo (Febe) ante su resplandor se apaga, no luce. Eros, dios de la atracción, se escarcha de flores, resulta frío ante el poder de seducción de la mujer.

En otros momentos da algún dato más sobre el personaje en cuestión, como es el caso de su poema «El macho cabrío», donde Pan se presenta como su padre y al igual que Venus, a la que menciona con el nombre de Filomnedes (I, 149), nació de entre la espuma del mar. O su poema de tono burlesco «En Málaga», donde aparece la figura de Ceres para caracterizar la corpulencia de una mujer, «La suntuosa Leonarda», con la que da comienzo el poema, de la que dice: «viene tu culo / de Ceres en retórica de mármol» (I, 355). Lo que pretende el poeta, según Isabel Román (2003: 397), es en este caso parodiar «la consabida belleza de las estatuas de diosas clásicas».

\section{Simple transmisión del contenido de algunos referentes clásicos}

Finalmente, García Lorca tiene como idea básica transmitir únicamente el contenido de algunos referentes clásicos. Esto lo lleva a cabo tanto en su manifestación pictórica como en ofrecernos las claves que la tradición legó mediante un lenguaje en ocasiones descriptivo, en ocasiones sugeridor y en ocasiones imitativo.

Una muestra de lenguaje descriptivo la tenemos en su poema «Venus» de Tres estampas del cielo. Nos remite a dos cuadros, uno de Velázquez, La Venus del espejo, y otro seguramente de Tiziano, La Venus de Urbino. Normalmente se ha considerado que García Lorca solo se ha fijado en el primero de los cuadros mencionados y el poema viene a ser una descripción o traslación del mismo. Pero si leemos con atención el poema, Lorca habla de dos grandes senos, que no aparecen en La Venus del espejo pero sí en La Venus de Urbino, e igualmente sucede con los versos «llevar la mano de iris / a tu sexo» (I, 869). Un invento del poeta y que no está presente en ninguno de los dos cuadros es el collar de perlas que, según su poema, lleva Venus al cuello. ${ }^{14}$

El lenguaje se vuelve sugeridor en el poema «La Sibila» ${ }^{15}$ impregnado todo él de duda y misterio, principales ideas connotativas con las que la Antigüedad

14. Rafael Alberti, como es sabido, era un maestro en trasladar a poesía algunos de los cuadros que veía en el Museo del Prado.

15. García Lorca en su conferencia «El cante jondo. Primitivo canto andaluz» habla de la Sibila, «verdadera esfinge de Andalucía», en referencia a la pregunta que late en el fondo de todos los poemas del cante jondo, «terrible pregunta sin contestación». La Sibila viene a representar en Lorca el misterio, la pregunta sin respuesta, el planteamiento de «un hondo problema emocional» sin solución, o teniendo como única salida la muerte, «que es la pregunta de las preguntas» (III, 205-206). Por esta razón en otro poema de tan solo ocho versos, «Ella», 
asociaba a estos personajes. La más famosa fue la Sibila de Cumas. Vivían en cuevas y los antiguos pensaban que adivinaban el futuro bajo la inspiración de Apolo. En realidad, emitían unos sonidos y gritos en el interior de la cueva que se prestaban a cualquier interpretación. Para sugerirnos estas ideas, García Lorca lo construye en torno a una «puerta cerrada» (I, 1109) que hará de frontera entre el exterior y el interior, sembrando la duda y la angustia, hay que sobreentender ante el futuro.

El caso contrario nos lo ofrece su poema «Nocturno de marzo. Encuentro». El lenguaje de algunos de sus versos es ahora imitativo prácticamente onomatopéyico. Mediante una serie de repeticiones trata de imitar al eco:

¡Oh Diablo,

Diablo,

Diablo!

¿Quién diría que eras

blanco,

blanco,

blanco?

¿Quién diría que eres

santo

santo

santo?

El Eco de los ecos

gira sobre mi cuarto. (I, 1021)

\section{Conclusión}

El análisis llevado a cabo nos ha permitido sacar a la luz los fundamentos o ideas nucleares más significativas sobre las que es posible organizar y dar cuenta de la presencia, en su gran mayoría, en la poesía de García Lorca de todo un mundo procedente de la Antigüedad greco-latina El poeta se sirve, como primera idea central, de la comparación e identificación, procedimientos al alcance de cualquier poeta, a los que imprime su sello personal. Con ello pone en un mismo plano de igualdad tanto a seres animados como a inertes, incluso a la propia voz lírica, con personajes y figuras del mundo clásico elevándolos a la categoría míti-

que tiene como protagonista a la Sibila, termina con este par de versos: «(Oh, procesión / de preguntas)» (I, 1104). 
ca. Una segunda idea central que permite dar cuenta de la presencia de figuras mitológicas es su clara intención de modificarlas y transformarlas en un juego poético de gran belleza. Para ello suprime elementos que le ofrecía la tradición clásica y los sustituye por otros productos de su imaginación, o bien añade algún elemento nuevo, o metamorfosea la figura del mundo antiguo. Una tercera idea central tiene como objetivo servirse de figuras mitológicas con la finalidad de ir en apoyo del contenido poemático o de crear un clima poético propio de la Antigüedad. Lo lleva a cabo mediante un sistema de asociaciones que le viene dado al poeta por la tradición cultural. Pero no se limita a ello el poeta: las figuras mitológicas también van en apoyo de un núcleo temático con el que nada tienen que ver, delineando una relación meramente subjetiva que también sirven para caracterizar con más precisión a otro personaje mitológico como la mujer lejana. Finalmente, a partir de la cuarta idea central el poeta da a conocer el contenido de algunos referentes clásicos mediante un lenguaje descriptivo, como la Venus que aparece en los cuadros de Velázquez y Tiziano; un lenguaje sugeridor inspirado en la figura mitológica, como la Sibila; o incluso un lenguaje onomatopéyico imitando al eco.

\section{Referencias bibliográficas}

Aguilar Fernández, R. M. (1998): «El mito griego en la poesía de García Lorca», Cuadernos de Filología Clásica (Estudios griegos e indoeuropeos) 8: 75-102.

Alberti, R. (1988): Obras completas. Tomo II: Poesía 1939-1963, García Montero, L. (ed.), Madrid, Aguilar.

Camacho Rojo, J. M. (2006): «Apuntes para un estudio de la tradición clásica en la obra de Federico García Lorca», en CAMACho RoJo, J. M. (ed.) (2006): La tradición clásica en la obra de Federico García Lorca, Granada, Universidad de Granada. 87-111.

Cristóbal López, V. (2006): «Imágenes lorquianas de cuño clásico: metonimias y metáforas mitológicas», en CAмAсho RoJo, J. M. (ed.) (2006): La tradición clásica en la obra de Federico García Lorca, Granada, Universidad de Granada. 185-198.

García Lorca, F. (1985): Oda y burla de Sesostris y Sardanápalo, GarcíaPosada, M. (ed.), Ferrol, Sociedad de Cultura Valle-Inclán.

- (1987): Obras completas III Prosa-Dibujos, Del Hoyo, A. (ed.), Madrid, Aguilar.

- (1992): Obras Completas I. Verso. Prólogo de Jorge Guillen, DEL Hoyo, A. (ed.), 22a edición, Madrid, Aguilar. 
- (2010): Poeta en Nueva York, Clementa Millán, M. (ed.), $16^{\text {a }}$ edición, Madrid, Cátedra.

García LorCA, F. (1980): Federico y su mundo, Madrid, Alianza Editorial.

García Montero, L. (1996): La palabra de Ícaro. Estudios literarios sobre García Lorca y Alberti, Granada, Universidad de Granada.

García-PosadA, M. (1982): Lorca: interpretación de Poeta en Nueva York, Madrid, Akal.

Gullón, R. (1958): Conversaciones con Juan Ramón, Madrid, Taurus.

Grimal, P. (1966): Diccionario de la mitología griega y romana, $3^{\mathrm{a}}$ edición, Barcelona, Labor.

Jiménez, J. R. (1990): Ideolojía. Metamorfosis IV, en SánChez Romeralo, A. (ed.), Barcelona, Anthropos.

Márquez, M. A. (1994): «Afrodita y Narciso», en Gómez Canseco, L. (ed.) (1994): Las formas del mito en las literaturas hispánicas del siglo XX, Huelva, Universidad de Huelva. 135-151.

Menarini, P. (1986): «El primer soneto de García Lorca», en DAVID KossofF, A.; R. H. Kossoff; G. Ribbans; J. Amor y VÁzquez (eds.): Actas del viII Congreso de las Asociación internacional de Hispanistas, Madrid, Istmo. 287-294.

Ortega Garrido, A. (2012): Vanguardia y mundo clásico grecolatino en España, Madrid, Estudios de la Cultura de España.

Román Román, I. (2003): «Los mitos clásicos en la poesía de Federico García Lorca», Anuario de Estudios Filológicos, vol. XXVI: 387-405.

Salazar Rincón, J. (1999): "Rosas y mirtos de luna...». Naturaleza y símbolo en la obra de Federico García Lorca, Madrid, Universidad Nacional de Educación a Distancia. 